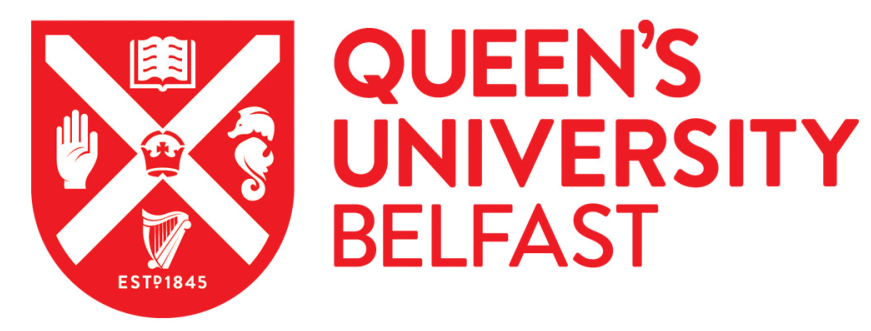

\title{
Applying neutron diffraction with isotopic substitution to the structure and proton-transport pathways in protic imidazolium bis\{(trifluoromethyl)sulfonyl\}imide ionic liquids
}

Turner, A. H., Imberti, S., Swadzba-Kwasny, M., \& Holbrey, J. D. (2018). Applying neutron diffraction with isotopic substitution to the structure and proton-transport pathways in protic imidazolium bis\{(trifluoromethyl)sulfonyl\}imide ionic liquids. Faraday Discussions, 206, 247-263.

https://doi.org/10.1039/c7fd00143f

\section{Published in:}

Faraday Discussions

Document Version:

Peer reviewed version

Queen's University Belfast - Research Portal:

Link to publication record in Queen's University Belfast Research Portal

\section{Publisher rights}

(C) 2017 The Royal Society of Chemistry.

This work is made available online in accordance with the publisher's policies. Please refer to any applicable terms of use of the publisher

\section{General rights}

Copyright for the publications made accessible via the Queen's University Belfast Research Portal is retained by the author(s) and / or other copyright owners and it is a condition of accessing these publications that users recognise and abide by the legal requirements associated with these rights.

Take down policy

The Research Portal is Queen's institutional repository that provides access to Queen's research output. Every effort has been made to ensure that content in the Research Portal does not infringe any person's rights, or applicable UK laws. If you discover content in the

Research Portal that you believe breaches copyright or violates any law, please contact openaccess@qub.ac.uk. 


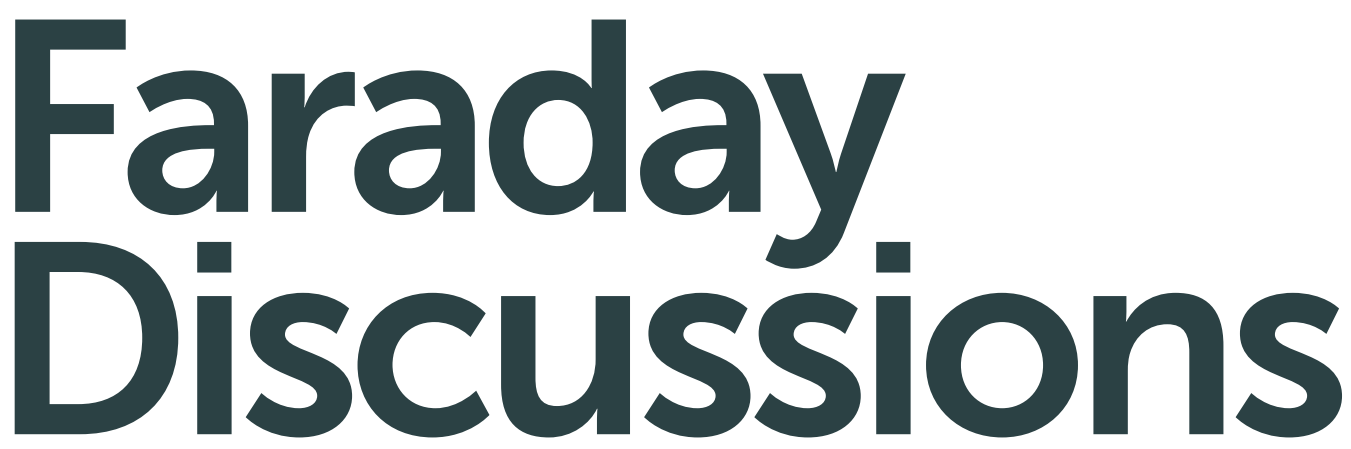

\section{Accepted Manuscript}

This manuscript will be presented and discussed at a forthcoming Faraday Discussion meeting.

All delegates can contribute to the discussion which will be included in the final volume.

Register now to attend! Full details of all upcoming meetings: http://rsc.li/fd-upcoming-meetings

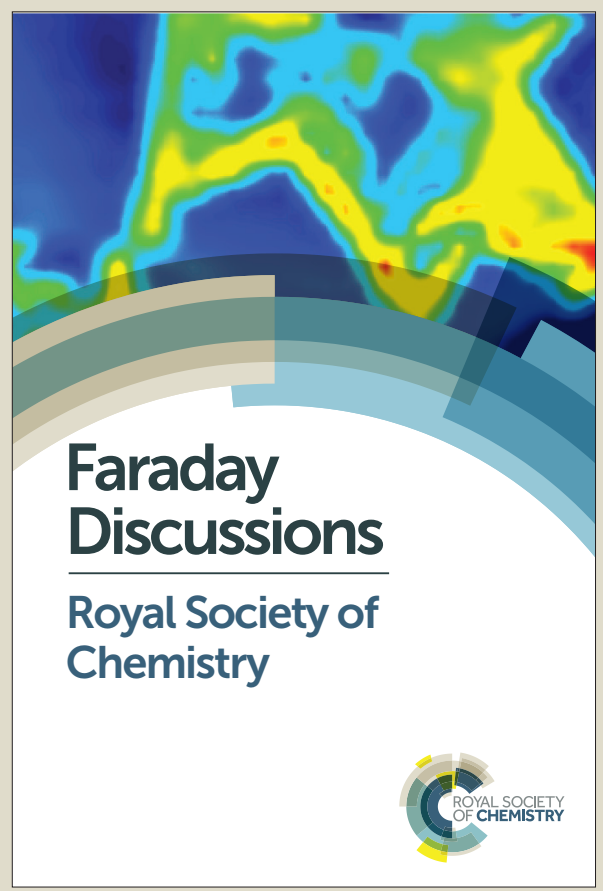

This is an Accepted Manuscript, which has been through the Royal Society of Chemistry peer review process and has been accepted for publication.

Accepted Manuscripts are published online shortly after acceptance, before technical editing, formatting and proof reading. Using this free service, authors can make their results available to the community, in citable form, before we publish the edited article. We will replace this Accepted Manuscript with the edited and formatted Advance Article as soon as it is available.

You can find more information about Accepted Manuscripts in the Information for Authors.

Please note that technical editing may introduce minor changes to the text and/or graphics, which may alter content. The journal's standard Terms \& Conditions and the Ethical guidelines still apply. In no event shall the Royal Society of Chemistry be held responsible for any errors or omissions in this Accepted Manuscript or any consequences arising from the use of any information it contains.

This article can be cited before page numbers have been issued, to do this please use: A. H. Turner, S. Imberti, M. Swadzba-Kwasny and J. D. Holbrey, Faraday Discuss., 2017, DOI: 10.1039/C7FD00143F. 


\title{
Journal Name
}

\section{ARTICLE TYPE}

Cite this: DOI: $10.1039 /$ xxxxxxxxxx

\section{Applying neutron diffraction with isotopic substitu- tion to the structure and proton-transport pathways in protic imidazolium bis\{(trifluoromethyl)sulfonyl\}imide ionic liquids ${ }^{\dagger}$}

\author{
Adam H. Turner ${ }^{a}$ Silvia Imberti, ${ }^{b}$ Małgorzata Swadźba-Kwaśny, ${ }^{a}$ John D. Holbrey ${ }^{a *}$
}

Received Date

Accepted Date

DOI: $10.1039 / x x x x x x x x x x$

www.rsc.org/journalname

\begin{abstract}
Neutron diffraction with isotopic substitution has been applied to examine the potential for complex-ion formation in protic imidazolium bis\{(trifluoromethyl)sulfonyl\}imide ionic liquids. Strong cation-anion hydrogen-bonding in the 1:1 base:acid ionic liquid results in a high population of anions adopting a cis-conformation and, on adding excess imidazole (2:1 base:acid stoichiometry), cation-base and base-base correlations were identified however, persistent hydrogen-bond associations were not observed.
\end{abstract}

\section{Introduction}

Protic ionic liquids (PILs) ${ }^{1}$ can be readily prepared by simple acid-base hydrogen-transfer reactions; $\mathrm{A}-\mathrm{H}+\mathrm{B} \longrightarrow[\mathrm{BH}]^{+}+$ $[\mathrm{A}]^{-}$. In most cases, there are implicit assumptions that a $1: 1$ acid:base stoichiometry is used and that the equilibrium lies far to the right, i.e. that the liquid generated is, in fact, a fully ionised ionic liquid. Neither of these two cases are necessarily true. In the context of strong acids and bases, full proton transfer usually occurs. However, large regions of potentially interesting liquid phase space are available when PILs are prepared with compositions other than that of the neutral salt (using excess of acid or base). Such regions of Such regions of the PIL phase space can correspond to the important regions of 'acidity' and 'basicity' in aprotic chlorometallate ionic liquids. ${ }^{2}$ Watanabe and coworkers ${ }^{3}$ and Angell and co-workers ${ }^{4}$ have both made major contributions to the study of PILs formed with combinations of strong acids and bases (empirically with differences in pKa values in excess of 8-10), demonstrating that interesting, and useful, ionic liquids can be generated at compositions that do not have notional 1:1 acid:base stoichiometry.

For example, 1-H-imidazolium bis\{(trifluoromethyl)sulfonyl\}imide ([im] $\left.\left[\mathrm{NTf}_{2}\right]\right)$, prepared by the reaction of imidazole with bis(trifluoromethyl)sulfonylimidic acid (Fig. 1) forms a stable protic salt at 1:1 (mp $\left.74{ }^{\circ} \mathrm{C}\right)$. On addition of

\footnotetext{
${ }^{a}$ School of Chemistry and Chemical Engineering, The Queen's University of Belfast, Belfast, BT9 5AG, Northern Ireland. Tel: +44 (0) 289097 4836; E-mail: j.holbrey@qub.ac.uk

${ }^{b}$ ISIS, Rutherford Appleton Laboratory, Harwell Science \& Innovation Campus, Didcot, Oxfordshire, OX11 ODE

$\dagger$ Electronic Supplementary Information (ESI) available: See DOI: 10.1039/b000000x/
}

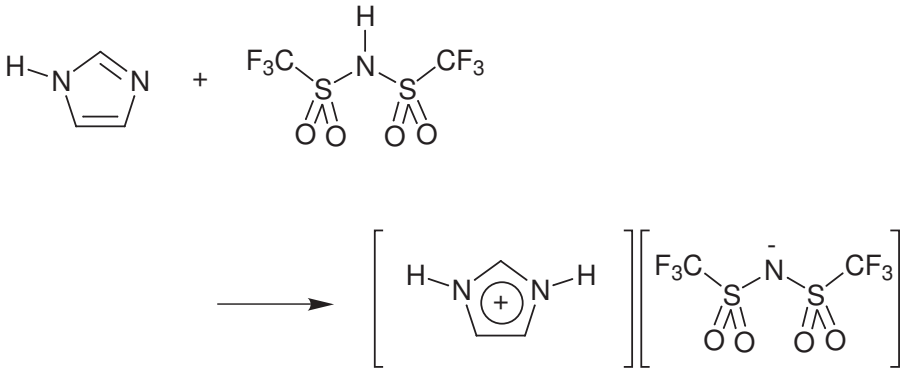

Fig. 11- $H$-imidazolium bis\{(trifluoromethyl)sulfonyl\}imide prepared from imidazole and bis\{(trifluoromethyl)sulfonyl\}imidic acid.

either additional $\mathrm{H}\left[\mathrm{NTf}_{2}\right]$ or imidazole, two extended liquid regions with depressed melting points (Fig. 2) are formed. Interestingly, both these regions have better conductivity and proton transport properties than those of the 1:1 salt composition. Non-stoichiometric PILs are of interest as non-aqueous proton conductors, ${ }^{3,5-11}$ particularly as water-free electrolytes in batteries, fuel cells, solar cells, actuators, or double-layer capacitors. For fuel cell applications, the potential to combine good proton conductivity with enhanced thermal ranges (larger than are possible with aqueous electrolytes) has immense appeal. Indeed, PILs have been extensively studied for uses in fuel cells, and the most promising cases have base-rich compositions. ${ }^{8,10,11}$

Transport mechanisms in imidazole/H[NTf $\left.\mathrm{N}_{2}\right]$ PILs have been investigated using pulsed-field gradient NMR and quasi-elastic neutron scattering studies ${ }^{12}$ identifying both short range (Grotthuss) proton hopping and long range (diffusive) pathways. Oligomeric $\mathrm{im}-\mathrm{H} \cdots\left[\mathrm{H}-\mathrm{im}^{+}-\mathrm{H}\right] \cdots \mathrm{im}-\mathrm{H}$ chains were implicated in the extended proton transfer mechanism. Chong et al. ${ }^{13}$ also 


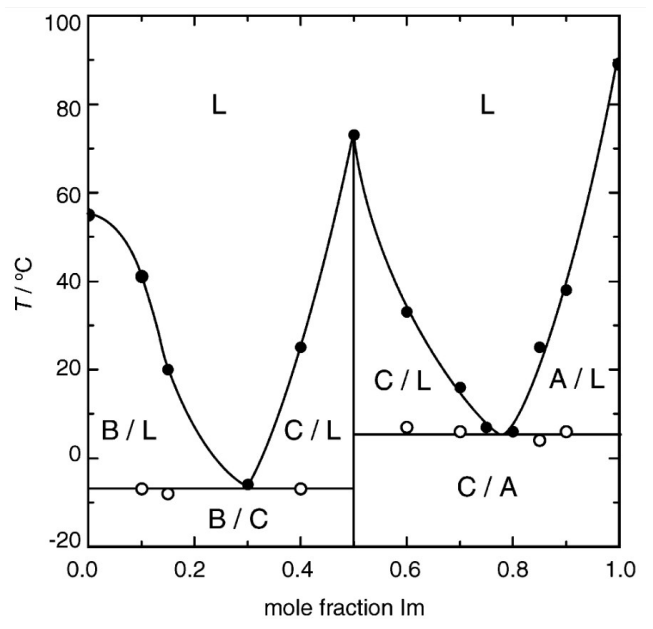

Fig. 2 Large liquid regions are present in the phase diagram for imidazole/H[NTf $\left.{ }_{2}\right]$ PIL mixtures with clear evidence for formation of the fully ionised salt ( $\mathrm{C}$ at 0.5 mole fraction) and eutectic regions with excess acid or base. Figure reprinted with permission from Noda et al. ${ }^{5}$ copyright 2003 American Chemical Society.

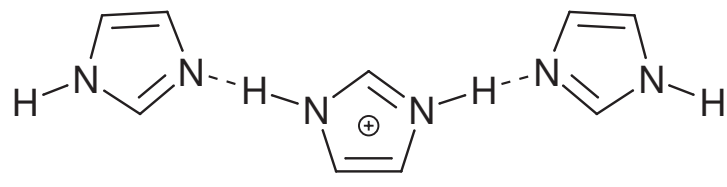

Fig. 3 Hydrogen-bonded complex cations of the form $[\mathrm{H}-\mathrm{im} \cdots \mathrm{H}-\mathrm{im}-\mathrm{H} \cdots \mathrm{im}-\mathrm{H}]^{+}$could be formed in the $2: 1$ base:acid system mixtures. $\mathrm{N}-\mathrm{H} \ldots \mathrm{H}$ hydrogen-bonded chains have been proposed as a mode for Grotthuss proton transfer in PILs. ${ }^{12,13}$

proposed Grotthuss-type mechanisms for protonic charge transfer between 2-methylimidazolium cations and unprotonated base (Fig. 3) including transport of protons across the imidazolium face as a mechanism in PILs to explain the apparent gains in conductivity, allowing protonic charge to cross a series of hydrogen bonds without large-scale movement of the cations.

The liquid structure of the PIL base-rich phase space has not been extensively studied. It seems appealing to invoke the formation of homo-conjugated cations of the form $[\mathrm{B} \cdots \mathrm{H} \cdots \mathrm{B}]^{+}$, as above, in the base-rich phase space of PILs. Such species have been identified in the solid state, for example in crystals of a 1,2dimethylimidazolium chloride:1,2-dimethylimidazole adduct ${ }^{14}$ and in low temperature solutions studies for homo-dimers of pyridine/1-H-pyridinium salts. ${ }^{15}$

We have an on-going interest in understanding the role of ionassociation and speciation in ionic liquids ${ }^{16-18}$ and the nature of the 'complex ions' that can be formed when acids and bases, or salts and acids or bases are mixed. ${ }^{19-21}$ Here, we compare the liquid structures of $1: 1$ and 2:1 base:acid mixtures of imidazole with $\mathrm{H}\left[\mathrm{NTf}_{2}\right]$, determined using neutron diffraction with isotopic substitution, in order to identify whether persistent homo-conjugated complex cations can be observed in the basic-rich region of phase space and, if present, to try to understand how these contribute to the liquid structure and proton conductivity.
View Article Online

Table 1 Experimental sample compositions, indidating the the molẩ r ratio of imidazole to acid and the isotopic composition of the components added.

\begin{tabular}{clcc}
\hline & Ratio & Imidazole & Acid \\
\hline $\mathbf{1}$ & $1: 1$ & $\mathrm{H}$ & $\mathrm{H}$ \\
$\mathbf{2}$ & & $\mathrm{H} / \mathrm{D}$ & $\mathrm{H} / \mathrm{D}$ \\
$\mathbf{3}$ & & $\mathrm{D}$ & $\mathrm{D}$ \\
$\mathbf{4}$ & $2: 1$ & $\mathrm{H}$ & $\mathrm{H}$ \\
$\mathbf{5}$ & & $\mathrm{H} / \mathrm{D}$ & $\mathrm{H} / \mathrm{D}$ \\
$\mathbf{6}$ & & $\mathrm{D}$ & $\mathrm{D}$ \\
$\mathbf{7}$ & & $\mathrm{D}$ & $\mathrm{H}$ \\
\hline
\end{tabular}

\section{Experimental}

Protiated and deuteriated bis(trifluoromethyl)sulfonylimidic $\operatorname{acid}^{22}\left(\mathrm{H}\left[\mathrm{NTf}_{2}\right]\right.$ and $\left.\mathrm{D}\left[\mathrm{NTf}_{2}\right]\right)$ were prepared by the reaction of $\mathrm{Li}\left[\mathrm{NTf}_{2}\right]$ with conc sulfuric and deuteriated-sulfuric acid respectively. The acids were obtained as pure, colourless crystalline solids after sublimation from the reaction mixtures and were then isolated and stored under argon. Imidazole- $\mathrm{H}_{4}$ and imidazole- $\mathrm{D}_{4}$ were purchased from SigmaAldrich and used as received.

In order to take advantage of the different neutron scattering contrasts available, samples at 1:1 and 2:1 imidazole:acid molar ratio were prepared with a series of $\mathrm{H} / \mathrm{D}$-isotopomeric contrasts (Table 1). All-D, all-H and 1:1 H/D mixed samples were prepared from imidazole- $\mathrm{D}_{4}$, imidazole- $\mathrm{H}_{4}$ or mixtures of the two, with either $\mathrm{H}\left[\mathrm{NTf}_{2}\right]$ or $\mathrm{D}\left[\mathrm{NTf}_{2}\right]$. An additional sample (7 in Table 1) from imidazole- $\mathrm{D}_{4}$ and $\mathrm{H}\left[\mathrm{NTf}_{2}\right]$ was also run to provide isotopic contrast between the $\mathrm{C}-\mathrm{H}$ and $\mathrm{N}-\mathrm{H}$ sites in the 2:1 system. Mixtures of base + acid were prepared by mixing accurately weighed quantities of the respective heterocyclic bases and the acids at 1:1 and 2:1 molar ratios into vials containing a magnetic stir bar. The vials were then sealed under argon, and heated with stirring at $80{ }^{\circ} \mathrm{C}$ to homogenise the samples. The 2:1 imidazole:acid mixtures were liquid under ambient conditions, the 1:1 imidazole:acid samples were crystalline solids and the mp of the protic sample ( 1 in Table 1 ) was $74{ }^{\circ} \mathrm{C}$, consistent with that reported by Noda et al. ${ }^{5}\left(73{ }^{\circ} \mathrm{C}\right)$ and Moschovi et al. ${ }^{23}\left(72.76{ }^{\circ} \mathrm{C}\right)$. The melting point of deuteriated 1:1 imidazole:acid was ca. $85^{\circ} \mathrm{C}$.

Neutron scattering data were collected on the seven samples (Table 1) using the SANDALS spectrometer at the ISIS pulsed neutron and muon source at the Rutherford Appleton Laboratory, UK, using $1 \mathrm{~mm}$ 'null scattering' $\mathrm{Ti}_{0.68} \mathrm{Zr}_{0.32}$ flat plate cells, maintained at $90{ }^{\circ} \mathrm{C}$. The method used for data reduction using GUDRUN, ${ }^{24}$ and analysis using the Empirical Potential Structure Refinement (EPSR) program ${ }^{25,26}$ have been described in previous reports. 27,28

Imidazole and imidazolium moieties were described using a simple molecular descriptors with atom types defined based on the unique positions in the molecular skeleton of the moieties, as shown in Figure 4. EPSR simulation models were refined against the experimental data over the full data range $\left(Q=0.1-50 \AA^{-1}\right)$ using a reference potential derived from OPLS-AA parameters with charges scaled by 0.50 , are given in Table 2 . It has previously been shown 29,30 that charges determined from isolated gas phase calculations need to be reduced in order to adequately rep- 
Table 2 Lennard-Jones well depth $(\varepsilon)$, range $(\sigma)$, and charge $(q)$ parameters used for the reference potential of the Empirical Potential Structure Refinement model.

\begin{tabular}{lllr}
\hline Atom type & $\varepsilon\left(\mathrm{kJ} \mathrm{mol}^{-1}\right)$ & $\sigma(\AA)$ & $q(\mathrm{e})$ \\
\hline imidazole & & & \\
\hline NB1 & 3.2 & 0.7 & -0.2087 \\
CB1 & 3.7 & 0.8 & -0.1064 \\
CB2 & 3.7 & 0.8 & -0.17285 \\
HB1 & 0 & 0 & 0.2494 \\
NB2 & 3.2 & 0.7 & -0.1406 \\
HB2 & 0 & 0 & 0.18403 \\
\hline imidazolium & & & \\
\hline NC1 & 3.2 & 0.7 & -0.06545 \\
CC1 & 3.7 & 0.8 & 0.01945 \\
CC2 & 3.7 & 0.8 & -0.0412 \\
HC1 & 0 & 0 & 0.1586 \\
HC2 & 0 & 0 & 0.12557 \\
\hline [NTf $\left.{ }_{2}\right]^{-}$ & & & \\
\hline SA & 3.55 & 0.1046 & 0.5101 \\
CA & 3.50 & 0.2761 & 0.1750 \\
NA & 3.25 & 0.7113 & -0.3300 \\
OA & 2.65 & 0.8786 & -0.2650 \\
FA & 2.95 & 0.2218 & -0.0800 \\
\hline
\end{tabular}

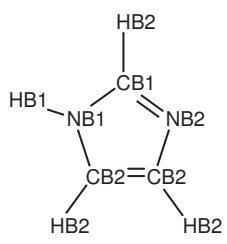<smiles>Cc1c(C=O)[n+](Cl)c(C=O)n1Cl</smiles>

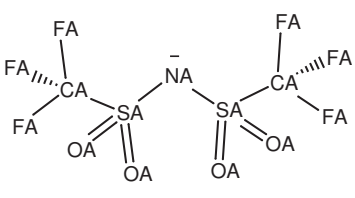

Fig. 4 Atom types used in the initial EPSR simulation models

resent condensed phases, typically to $80 \%$ of the integer value. Here we found, in some simulation cases, that using such relatively large partial charges for the 2:1 base:acid system lead to de-mixing of the [imidazolium] $\left[\mathrm{NTf}_{2}\right]$ ionic liquid and imidazole components in the EPSR simulation. This anomalous behaviour generated simulated $S(Q)$ data sets with large scattering components in the low $Q$ region that did not arise from fitting to the experimental data and were clearly an artefact. It was thought that one possible cause for this behaviour was over-association of the ionic components of the simulation box to the detriment of neutral imidazole-ion associations.

In order to address this, charges used were scaled to $50 \%$. With these smaller partial charges, no demixing was observed in any structure refinements and the cationic and neutral imidazolium/imidazole moieties respectively and described more similarly, which is reasonable since in the absence of an adaptive/reactive force field, the likely rapid hydrogen-transfer between the two heterocycles would render them approximately equivalent.

In addition to the reference potentials, the non-parameterised empirical potential was allowed to vary between 0 and $30 \mathrm{~kJ}$ $\mathrm{mol}^{-1}$ to refine the structure. Within the EPSR simulations the $\left[\mathrm{NTf}_{2}\right]^{-}$anion was modelled as previously described ${ }^{31}$ with no pre-constrained dihedral angles or restrictions to rotation.
View Article Online

Table 3 Intramolecular bond distance (Å) and bond-arnglepoag143F constraints used to define the basic structures of imidazole, and the imidazolium and $\left[\mathrm{NTf}_{2}\right]^{-}$ions in the initial EPSR simulation models.

\begin{tabular}{|c|c|c|c|}
\hline Bond Distance & $(\AA)$ & Bond Angle & $\left({ }^{\circ}\right)$ \\
\hline \multicolumn{4}{|l|}{ imidazole } \\
\hline NC1-CC1 & 1.373 & 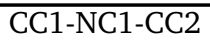 & 108.81 \\
\hline NC1-CC2 & 1.403 & CC1-NC1-HC1 & 125.46 \\
\hline NC1-HC1 & 0.998 & CC2-NC1-HC1 & 125.73 \\
\hline CC1-HC2 & 1.106 & NC1-CC1-NC1 & 108.26 \\
\hline CC2-CC2 & 1.402 & NC1-CC1-HC2 & 125.87 \\
\hline \multirow[t]{3}{*}{ CC2-HC2 } & 1.097 & NC1-CC2-CC2 & 107.07 \\
\hline & & CC2-CC2-HC2 & 130.37 \\
\hline & & NC1-CC2-HC2 & 122.56 \\
\hline \multicolumn{4}{|l|}{ imidazolium } \\
\hline NB1-CB1 & 1.401 & $\begin{array}{l}\text { CB1-NB1-CB2 } \\
\end{array}$ & 106.85 \\
\hline NB1-CB2 & 1.395 & CB1-NB1-HB1 & 126.89 \\
\hline NB1-HB1 & 0.984 & CB2-NB1-HB1 & 126.27 \\
\hline CB1-NB2 & 1.351 & NB1-CB1-NB2 & 111.22 \\
\hline CB1-HB2 & 1.094 & NB1-CB1-HB2 & 122.85 \\
\hline CB2-CB2 & 1.408 & NB2-CB1-HB2 & 125.92 \\
\hline CB2-HB2 & 1.088 & NB1-CB2-CB2 & 106.06 \\
\hline \multirow[t]{5}{*}{ NB2-CB2 } & 1.399 & CB2-CB2-HB2 & 129.88 \\
\hline & & NB1-CB2-HB2 & 122.55 \\
\hline & & CB1-NB2-CB2 & 105.86 \\
\hline & & NB2-CB2-CB2 & 110.02 \\
\hline & & NB2-CB2-HB2 & 121.61 \\
\hline \multicolumn{4}{|l|}{$\left[\mathrm{NTf}_{2}\right]^{-}$} \\
\hline SA-CA & 1.977 & CA-SA-NA & 99.42 \\
\hline SA-NA & 1.630 & CA-SA-OA & 105.69 \\
\hline SA-OA & 1.517 & NA-SA-OA & 114.33 \\
\hline \multirow[t]{4}{*}{ CA-FA } & 1.347 & OA-SA-OA & 115.22 \\
\hline & & SA-CA-FA & 111.29 \\
\hline & & FA-CA-FA & 107.59 \\
\hline & & SA-NA-SA & 127.67 \\
\hline
\end{tabular}

Simulations were equilibrated over ca. 2000-3000 cycles before accumulating and averaging data over a further 1000020000 interactions. The EPSR refinements, in each case, were initialised using an equilibrated Monte Carlo simulation containing either 1000 ions (imidazolium $+\left[\mathrm{NTf}_{2}\right]^{-}$for the $1: 1$ mixture) or 1500 species (imidazole, imidazolium, and $\left[\mathrm{NTf}_{2}\right]^{-}$anion for 2:1 mixture). The respective sizes of the simulation boxes corresponded to the experimentally determined molecular densities of the fully protiated mixtures. Centre of mass radial distribution functions were calculated using the SHARM routines within EPSR.

\section{Results and Discussion}

Neutron scattering measurements were performed on [imidazolium] [NTf ${ }_{2}$ ] PILs at $1: 1$ and 2:1 base:acid composition, at $90{ }^{\circ} \mathrm{C}$ (i.e. above the melting point of the $1: 1$ salt composition). EPSR analysis of the data was conducted fitting models containing equal ratios of cations and anions (1:1 system) or cations, anions, and neutral imidazole base (2:1 system) to the data sets from the three (1:1 system) or four (2:1 system) isotopically discrete samples. These models make the assumption that there is 'complete' proton transfer from an acid to the base, thus forming the ionic liquid. 

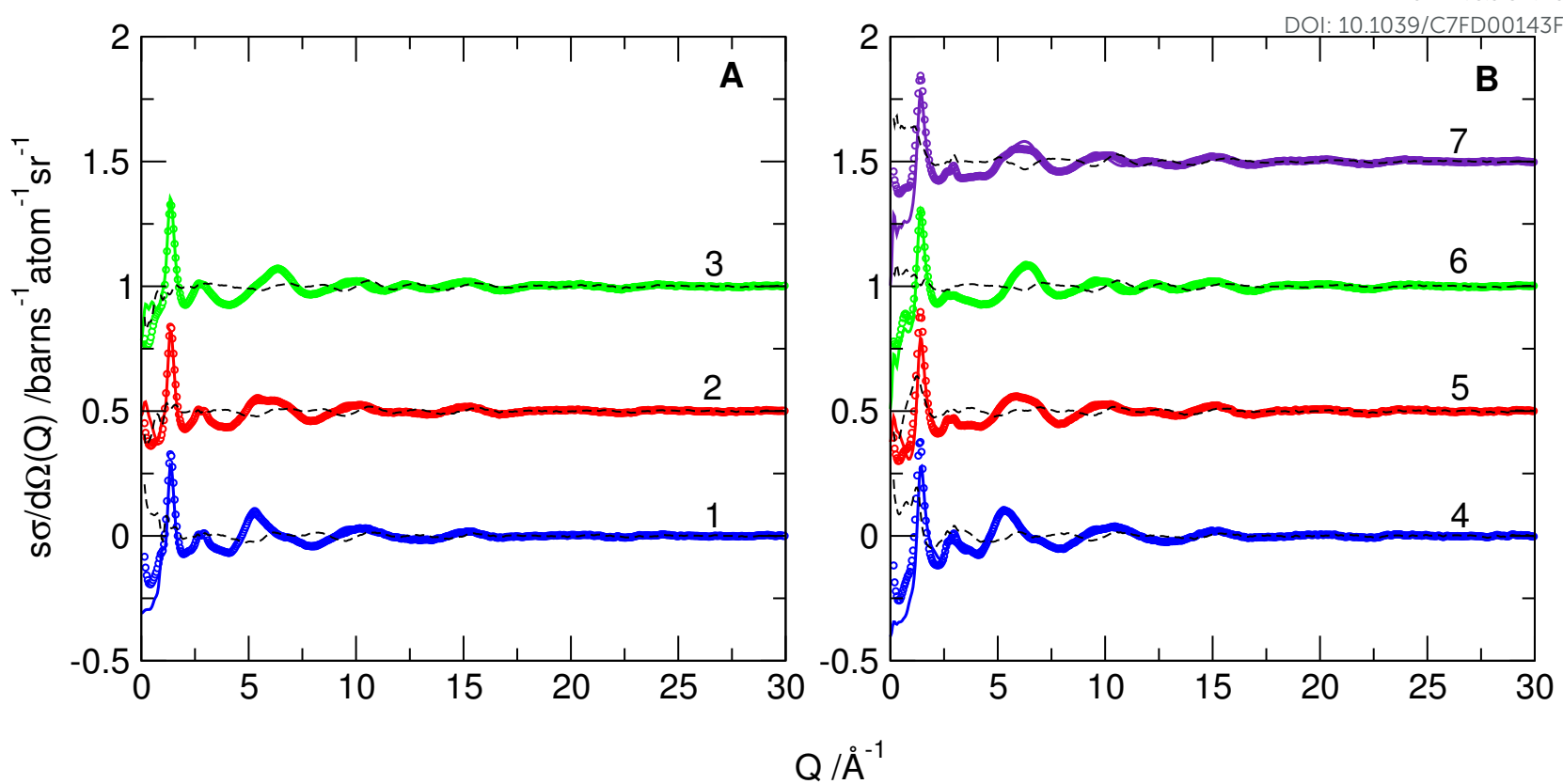

Fig. 5 Experimental $S(Q)$ data (symbols), EPSR models for the data (solid lines) and residual differences between simulated and experimental data (dashed lines) for the 1:1 imidazole:acid (A) and 2:1 imidazole:acid (B) systems studied. The data-set labels correspond to the samples with differing H/D-isotopic compositions as shown in Table 1.

Experimental neutron diffraction total scattering functions are presented in Fig. 5 together with the EPSR data and difference plots between the experimental and simulated data sets. In general, a good fit is observed for all isotropic substitutions between the experimental data and EPSR derived model indicating that, for both 1:1 and 2:1 systems, the models are self consistent with the multiple datasets.

\section{Centre-of-mass RDF analysis}

The corresponding centre-of-mass radial distribution functions (RDFs) for the 1:1 and 2:1 imidazole:acid systems derived from the EPSR models are shown in Fig. 6. It is apparent that the 1:1 system, modelled as a pure ionic liquid containing imidazolium cations and $\left[\mathrm{NTf}_{2}\right]^{-}$anions, shows the 'typical' ion-ion correlation patterns of a general ionic liquid with intermolecular ion-ion correlations dominating the observed $S(Q)$.

The first coordination shell of imidazolium cations contains anions at a contact distance of around $5.0 \AA$ (with two peaks in this distribution region at 4.2 and $5.6 \AA$ ) to the first shell minimum at ca. 7-8 $\AA$. The corresponding anion-anion RDF shows an outof-phase relationship to that from the cation-anion RDF, with a first maxima at $7.5 \AA$ and a minima at ca. $11 \AA$ concurrent with the second shell peak in the cation-anion RDF. Cation-cation RDF correlations also show a smaller peak at ca. 5-6 $\AA$ in the imidazolium first shell.

The 2:1 base:acid similarly shows ion-ion RDFs with a conservation of the same overall ion-ion correlation patterns between the two PILs. The RDFs show only minor perturbation by the presence of the additional imidazole added at 2:1, and first shell (to ca. $7.5 \AA$ ) association is observed between all the system components in these ionic liquids.

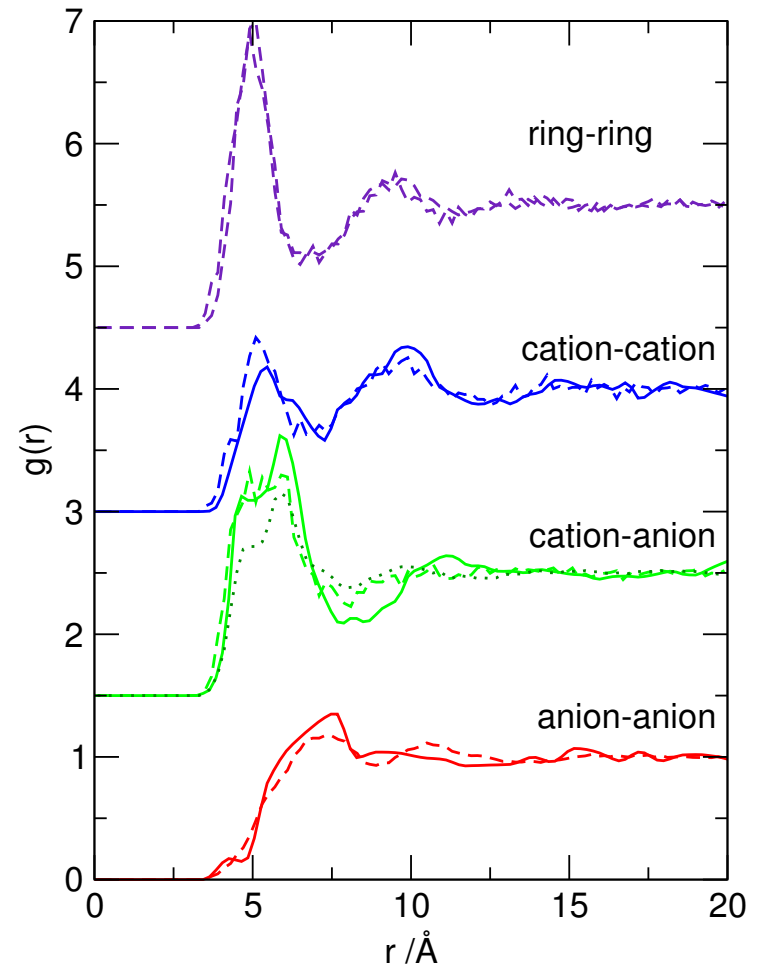

Fig. 6 Centre of mass RDFs for imidazole + acid systems showing cation-anion (green), cation-cation (blue) and anion-anion (red) correlations, with data for the 1:1 system shown as solid lines and for the 2:1 system as dashed lines, vertically offset for clarity. The heterocycle correlations for imizadole-cation and imidazole-imidazole in the 2:1 system (labelled ring-ring) show the identical RDFs for these two interactions. Imidazole-anion correlations (green dots) are also overlayed on the cation-anion RDF for comparison. 
Both imidazolium-imidazole and imidazole-imidazole correlations in the 2:1 system can be observed (shown offset in Fig. 6), both show a first maximum at 5-6 $\AA$, comparable to the imidazolium-imidazolium RDF, and at a distance compatible with a bridging hydrogen-bond between two imidazole rings in both cases at the edge of the first coordination shell. All three heterocycle-heterocycle RDFs show similar shapes with identical peak positions with smaller, and less well defined first peak in the imidazolium-imidazolium first correlation compared to those for the imidazole-imidazole and imidazolium-imidazole associations. This suggests intimate mixing of the two heterocycles (imidazole molecules and imidazolium cations) throughout the system with the absence of charge on imidazole enabling preferred access to both other imidazole and imidazolium sites compared to like-charged imidazolium-imidazolium interactions. The presence of two heterocycles per anion in the 2:1 system does not lead to any substantial perturbations of the cation-anion COM RDF compared to the 1:1 system, as shown in Fig. 6. The corresponding imdazole:anion COM RDF shows similar association (from $3.8 \AA$ to a minimum in the first shell at ca. $7.8 \AA$ ) however the peak is less intense, particularly in the shorter distance correlation regions below $5.0 \AA$.

Yaghini et al. ${ }^{32}$ have recently studied [1-ethylimidazolium] $\left[\mathrm{NTf}_{2}\right]+$ imidazole mixtures using IR spectroscopy and MD simulation. The results were interpreted in terms of extensive cation-anion, cation-imidazole and imidazole-anion hydrogen-bonding. The extent of cationimidazole hydrogen-bonding was reported to increase with increasing mole fraction of imidazole in the mixtures up to about 0.5 mole fraction (equivalent to 2:1 base:acid in the systems under investigation here) followed by an increase in imidazoleimidazole hydrogen-bonding at the expense of cation-imidazole and imidazole-anion interactions, implying domain separation of imidazole from the protic ethylimidazolium ionic liquid domains. Amines exhibit stronger basicity when dissolved in ionic liquids than in common molecular solvents, ${ }^{33}$ thus, addition of imidazole to the 1:1 PIL could lead to a large disruption of the (strong) cation-anion hydrogen-bonding motifs.

\section{Cation-anion correlation environments}

The spatial relationship between near-neighbouring sites can be highlighted by examining spatial density functions (SDFs). Imidazolium cation and $\left[\mathrm{NTf}_{2}\right]^{-}$anion spatial correlations around imidazolium centres for both the 1:1 and 2:1 systems, and the corresponding correlation space for imidazole molecules around imidazole and imidazolium centres in the 2:1 system are shown in Fig. 7, plotted to encompass the highest 15\% probability density for an interaction. A strong correlation of anions radially arrayed around the plane of the imidazolium cation, associated with the $\mathrm{C}-\mathrm{H}$ and $\mathrm{N}-\mathrm{H}$ sites, is evident with the greatest association to $\mathrm{N}-\mathrm{H}$ positions in both the $1: 1$ and 2:1 imidazolium:acid systems. The five lobes of high $\left[\mathrm{NTf}_{2}\right]^{-}$probability density within the equatorial plane of the imidazolium cation appear to be centred on the $\mathrm{X}-\mathrm{X}$ bonds $(\mathrm{X}=\mathrm{C}$ or $\mathrm{N})$ of the imidazolium ring. However, these associations arise from $\mathrm{X}-\mathrm{H} \cdots \mathrm{O}$ interactions whereas
View Article Online the anion centre-of-mass is situated close to to the $/ \mathrm{N}$ T atom centre.

Watanabe et al. ${ }^{34}$ have combined synchrotron high-energy Xray scattering studies on protic [imidazolium] $\left[\mathrm{NTf}_{2}\right.$ ] ionic liquids with MD simulation. SDFs calculated by MD indicated a marked preference for interactions of imidazolium N-H sites (containing the largest partial charge) with $\mathrm{O}$-atoms from the anion, with the $-\mathrm{CF}_{3}$ groups of the anion located above and below the imidazolium ring plane. Although F...cation SDFs were not determined in our studies here, it seems likely on steric grounds that the strongly $\mathrm{N}-\mathrm{H} \cdots \mathrm{O}$ hydrogen-bonded anions will sit around the imidazolium ring twisted out of the plane of the ring, furnishing the same spatial description.

The first shell of cation-cation correlations (between 3.3$6.6 \AA$ ) for the 1:1 system shows imidazolium-imidazolium correlations above and below the plane of the central imidazolium ring, i.e. occupying space not constrained by the equatorial cation-anion association.

The 2:1 system shows no significant changes in the cationanion SDFs compared to the case at 1:1. This indicates that the primary interactions are still hydrogen-bonding association of cations with anions in the plane of the cation. The cation-cation SDF now appears slightly less well defined, suggesting that the liquid lattice structure beyond the first correlation shell is less tightly constrained, most likely a consequence of dilution by the presence of imidazole.

The strong cation to anion hydrogen-bonding patterns that are evident in the spatial probability density plots (Fig. 7) occur primarily through pronounced interactions with the oxygen atoms of the anion. For the 1:1 system, this is most evident from the strong correlation peak at $1.9 \AA$ in the $\mathrm{N}-\mathrm{H} \cdots \mathrm{O}$ RDF, and a much smaller correlation at the same separation distance in the $\mathrm{N}-\mathrm{H} \cdots \mathrm{F}$ RDFs (shown in Fig. 8) There are no peaks in the $\mathrm{N}-\mathrm{H} \cdots \mathrm{N}$ RDF below 4 $\AA$. The coordination numbers association with these interactions are shown in Table 4.

For the 2:1 systems, also shown in Fig. 8, the corresponding imidazolium-anion ( $\mathrm{N}-\mathrm{H} \cdots \mathrm{O}) \mathrm{RDF}$ also shows a peak at $1.9 \AA$, although the intensity of this peak is lower than in the corresponding 1:1 case (the coordination number, indicating the number of $\mathrm{N}-\mathrm{H} \cdots \mathrm{O}$ interactions to $2.0 \AA$ is approximately $30 \%$ lower in the $2: 1$ system than in the $1: 1$ ). The first peak in the $\mathrm{N}-\mathrm{H} \cdots \mathrm{F}$ RDF (also at $1.9 \AA$ ) is larger than in the 1:1 case. This is discussed below, in terms of changes in the average anion conformation with composition. Again, there are no peaks in the $\mathrm{N}-\mathrm{H} \cdots \mathrm{N}$ RDF below $4 \AA$ A. Imidazole $\mathrm{N}-\mathrm{H} \cdots$ anion RDFs for the $2: 1$ system mimic those of the imidazolium cation, although the peak magnitudes (running coordination numbers) vary. The imidazole-F correlation is larger than that for imidazolium whereas the corresponding correlation to the $\mathrm{O}$ sites is smaller. The presence of similar imidazolium-anion and imidazole-anion interactions adds to the evidence for intimate mixing in the ionic liquid systems. Comparing the short distance ( $2 \AA$ ) $\mathrm{N}-\mathrm{H} \cdots \mathrm{N}$ coordination numbers, in both the 1:1 and 2:1 systems, each anion $O$ site participates as a hydrogen-bond acceptor in approximately 0.4 hydrogen-bonds to $\mathrm{N}-\mathrm{H}$ hydrogen-bond donors. In the 2:1 case, these are shared between imidazole and imidazolium donor sites. 

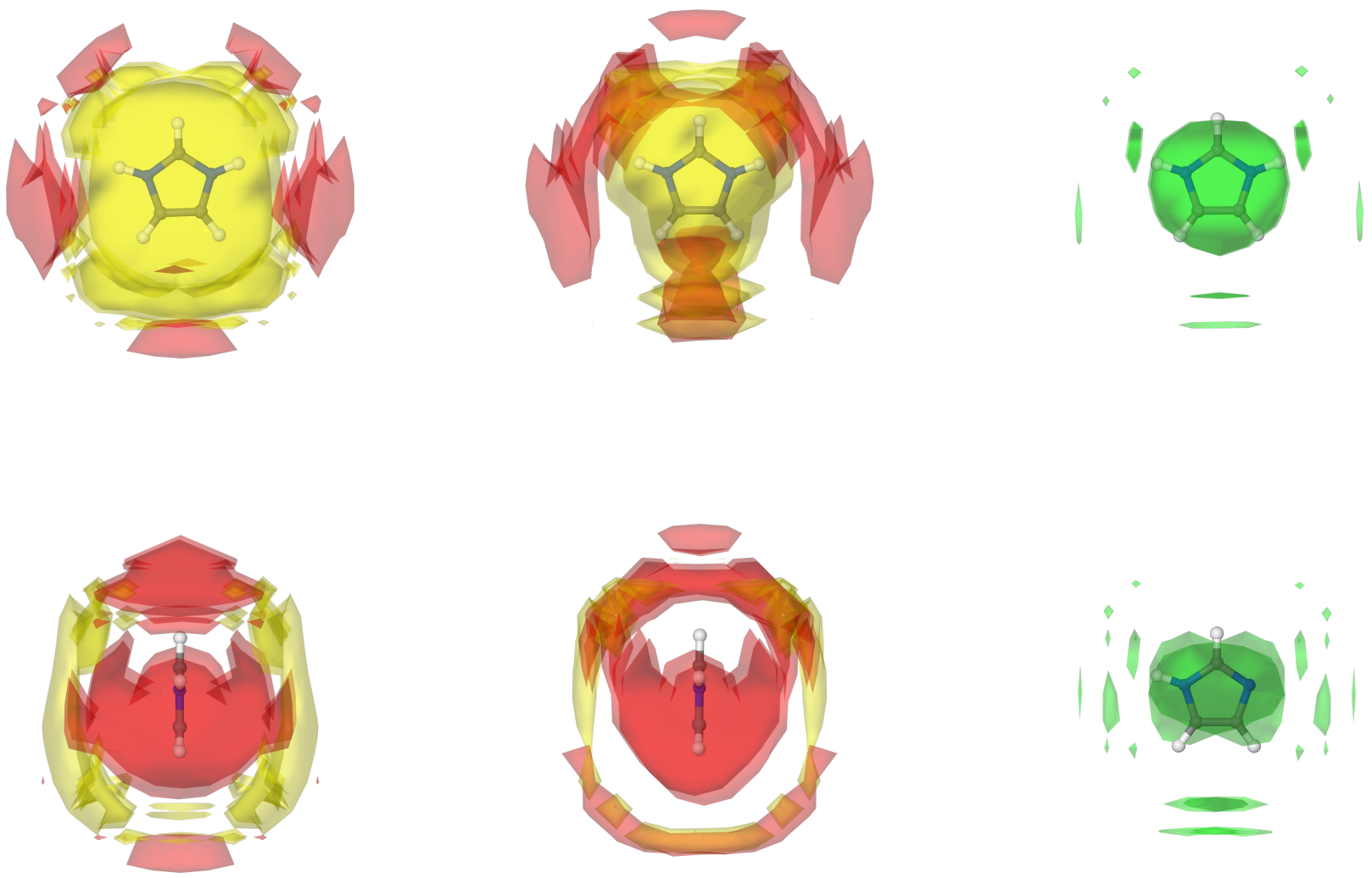

Fig. 7 SHARM spatial probability map for anions around central imidazolium cation (red) and imidazolium cations around a central cation (yellow) calculated to encompass the first shell peaks for both RDFs in Figure 6 showing the view over the imidazolium face (top) and edge-on (bottom) for 1:1 (left) and 2:1 (middle) mixtures. The corresponding imidazolium-imidazole (top right) and imidazole-imidazole COM SDFs (bottom right) for the 2:1 system are also shown. Surfaces were calculated to encompass the top 15\% probability within the first peak in the COM RDF between $3-8 \AA$.

Table 4 Running coordination numbers for hydrogen-bonding contacts from imidazolium and imidazole $\mathrm{N}-\mathrm{H}$ sites to $\left[\mathrm{NTf}_{2}\right]^{-}$anion $\mathrm{OA}, \mathrm{NA}$, and FA atoms over 2,3 , and $4 \AA\left(\mathrm{N}_{\text {imid }}-\mathrm{H}\right.$ is imidazolium, and $\mathrm{N}_{\mathrm{im}}-\mathrm{H}$ is imidazole).

\begin{tabular}{llllll}
\hline \multicolumn{2}{l}{ Donor } & \multicolumn{4}{c}{ Hydrogen bond acceptor } \\
& & $d / \AA$ & $\mathrm{O}$ & $\mathrm{N}$ & $\mathrm{F}$ \\
\hline $1: 1$ & $\mathrm{~N}_{\text {imid }}-\mathrm{H}$ & 2.0 & 0.389 & 0.012 & 0.115 \\
& & 3.0 & 1.292 & 0.215 & 0.748 \\
& & 4.0 & 2.965 & 0.668 & 2.846 \\
\hline $2: 1$ & $\mathrm{~N}_{\text {imid }}-\mathrm{H}$ & 2.0 & 0.229 & 0.003 & 0.143 \\
& & 3.0 & 0.820 & 0.088 & 0.672 \\
& & 4.0 & 2.192 & 0.419 & 2.570 \\
& $\mathrm{~N}_{\mathrm{im}}-\mathrm{H}$ & 2.0 & 0.174 & 0.002 & 0.155 \\
& & 3.0 & 0.696 & 0.076 & 0.838 \\
& & 4.0 & 1.810 & 1.810 & 2.618 \\
\hline
\end{tabular}

\section{The anion environment}

In aprotic ionic liquids with $\left[\mathrm{NTf}_{2}\right]^{-}$anions previously studied, ${ }^{18}$ free rotation of the anion around the $\mathrm{SO}_{2}-\mathrm{N}-\mathrm{SO}_{2}$ bonds leads to a statistical distribution of conformations, which are generally described as cis or trans, based on the relative positions of the two $-\mathrm{CF}_{3}$ groups.
In contrast to aprotic $\left[\mathrm{NTf}_{2}\right]^{-}$ionic liquids which typically have a statistical distribution of anion conformers, Moschovi et al. ${ }^{23}$ have shown that strong cation-anion hydrogen-bonding present in protic [imidazolium] $\left[\mathrm{NTf}_{2}\right.$ ] PILs results in a restriction in anion cis-trans interconversion with the energy barrier to cis:trans transformation of $\Delta H_{e q}=14.3 \mathrm{~kJ} \mathrm{~mol}^{-1}$. This leads to a promotion of the cis-anion population and also to the cis-anion conformer becoming more prevalent with increasing temperature.

In EPSR (and other simulations), the cis:trans conformer ratio can be assessed by examination of the distribution of intramolecular $\mathrm{CF}_{3} \ldots \mathrm{CF}_{3}$ distance distributions in the simulation model. The anion $\mathrm{CF}_{3} \cdots \mathrm{CF}_{3}$ distance distributions shown in Fig. 9 reflect the conformational distributions in the two simulation models. By summing the number of conformers with a $\mathrm{CF}_{3} \cdots \mathrm{CF}_{3}$ separation less than, and greater than, $4.5 \AA$, cis:trans conformer populations can be estimated. In the 1:1 system, a 58:42 cis:trans ratio was found which changes to a more conventional 22:78 ratio in the 2:1 system, consistent with a higher degree of cationanion hydrogen-bonding to the anion oxygen sites at $1: 1$. Reduction in the cis-anion populations in the $2: 1$ system is consistent with a reduction in the magnitude of direct imidazolium-anion hydrogen-bonding as the imidazolium cations become more in- 

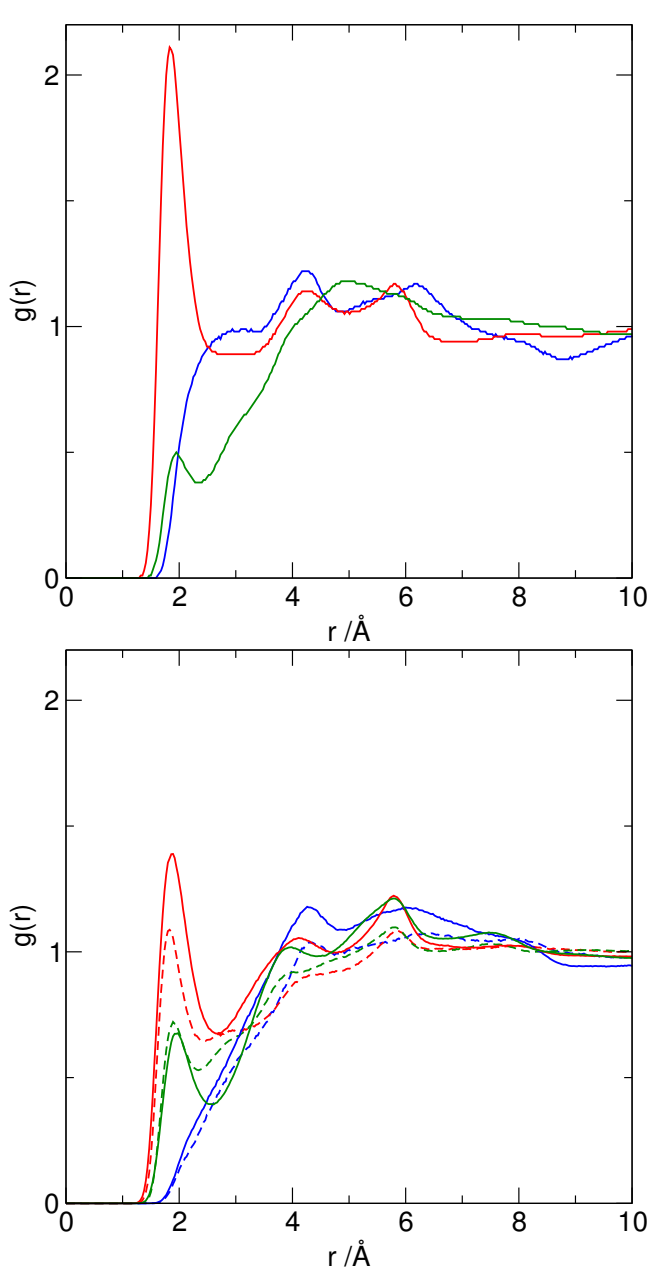

Fig. 8 Site-site RDFs for $\mathrm{N}-\mathrm{H}$ correlations from imidazolium (solid line) and imidazole (dashed line) to the anion oxygen (red), nitrogen (blue) and fluorine (green) sites of anions for 1:1 mixture (top) and 2:1 mixture (bottom). The pronounced $\mathrm{N}-\mathrm{H} \cdots \mathrm{O}$ correlations and the correspondingly poor interactions with the $\mathrm{CF}_{3}$-groups of the anion can be seen from both imidazolium and imidazole heterocycles in the systems.

teracting with adjacent imidazoles.

\section{Imidazole environment}

The correlations of imidazole molecules with both imidazole and imidazolium sites, indicated by the peak maximum at $5.0 \AA$ in their respective RDFs, are of great interest since these contacts appear at the separation distance consistent with edge-to-edge hydrogen-bonding and so should provide the mechanism for nondiffusive proton transport in these PILS. As previously noted, the $5.00 \AA$ correlation length present in both these RDFs corresponds to the separation distance between co-planar imidazole rings linked through an $\mathrm{N}-\mathrm{H} \cdots \mathrm{N}$ hydrogen-bond, and it would be convenient to infer that the RDFs provide clear evidence for hydrogen-bonding in the liquids. Indeed, hydrogen-bonding is generally invoked as a structural feature in base-rich imidazolium PILs and an important mechanism for proton transfer. ${ }^{12}$

Unfortunately, this static image of $\mathrm{N}-\mathrm{H} \cdots \mathrm{N}$ hydrogen-bonded chains of imidazolium and/or imidazole groups propagating through the liquid does not appear to be supported by the

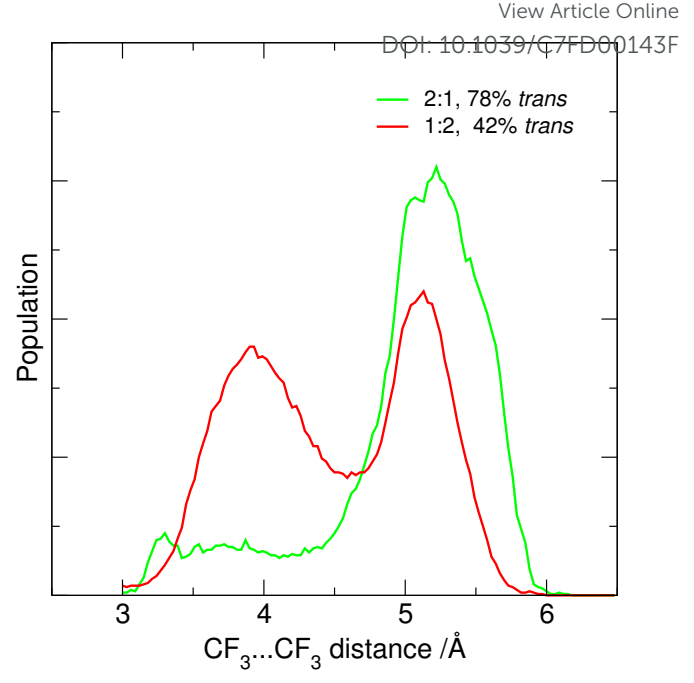

Fig. 9 Distribution of intramolecular $\mathrm{CF}_{3}-\mathrm{CF}_{3}$ distances within the $\left[\mathrm{NTf}_{2}\right]^{-}$anion in the two simulation models.

imidazolium-imidazole and imidazole-imidazole SDFs in Fig. 7 which indicate that the positions of highest probability for the heterocycle-heterocycle correlations are over (and directly below) the plane of the centre of reference ring (either imidazolium or imidazole) when plotted at the high $15 \%$ probability level.

This association pattern resembles that previously reported for stacking of aromatic guest molecules with aromatic cations of ionic liquid host solvents with a broad correlation in the respective RDFs starting from $c a$. $3 \AA$ with a peak around $5 \AA$. 17,28,35 However, in benzene and toluene the corresponding aromatic ring-ring correlations have been analysed in terms of a distribution of near neighbour orientations ranging from co-planar through to perpendicular. ${ }^{36}$

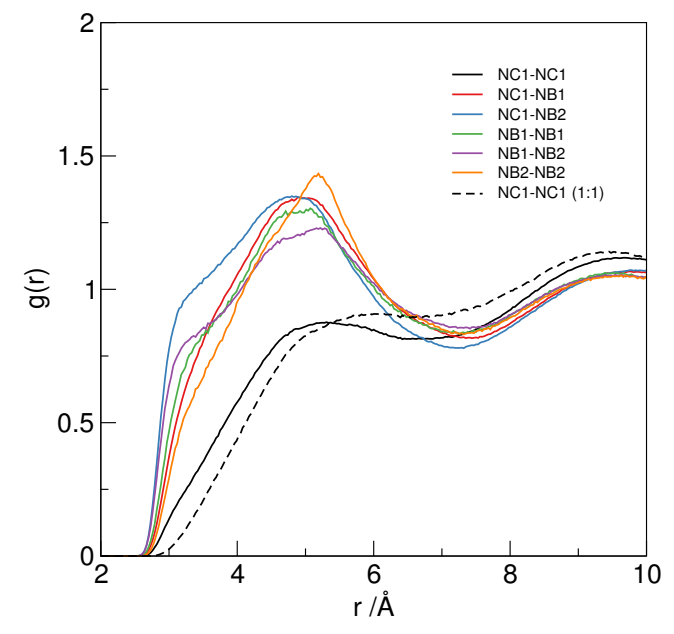

Fig. 10 Imidazolium-imidazolium, imidazolium-imidazole, and imidazole-imidazole N $\cdots \mathrm{N}$ site-site RDF correlations in the $2: 1$ system. The NC1-NC1 correlation from the 1:1 system is also shown as a dashed line for comparison.

Examining the $\mathrm{N} \cdots \mathrm{N}$ site-site RDFs to look for specific imidazole-imidazole and imidazole-imidazolium correlations (Fig. 10), the only evidence for hydrogen bonding is the presence of shoulders in the RDFs at about $3 \AA$ in the major first correla- 
tion peak that is centred around $5 \AA$ and reflects the position of the corresponding COM RDFs in Fig. 6. This lack of any strong evidence for hydrogen-bonding between heterocyclic components of the systems (imidazole or imidazolium) within the EPSR simulation, even through the COM RDFs do indicate that these moieties are positions close enough to each other to form $\mathrm{N} \cdots \mathrm{N}$ hydrogen bonded complexes can be interpreted in two ways. The first explanation is that there is simply insufficient information present within the experimental data to differentiate between the heterocycle $\mathrm{N}$ and $\mathrm{C}$ sites. It would be anticipated that even if this was the case, then the planar pentagonal rings would reveal an edge-edge preferred spatial correlation if persistent long-lived hydrogen-bonded complexes are present in the systems. The second possible explanation is that, while hydrogen-bonding is possible and is certainly an important part of the proton transfer mechanism, evidence for it's existence in the total structure refinement model is lost because the persistence time of hydrogen-bonded complexes is much smaller than that of slower reorientational inplace tumbling of the heterocyclic rings. The radius of gyration of imidazole/imidazolium rings separated by $5 \AA$ from their centres of mass is ideal to enable 'flipping' and transfer hydrogen atoms directly to adjacent heterocyclic $\mathrm{N}$-sites. The consequence of this is that only the average positions of the rings can be identified (as shown by the $5.0 \AA$ peak in the COM RDFs) but specific relative orientational correlations through $\mathrm{N}-\mathrm{H} \cdots \mathrm{N}$ hydrogen-bonds only occur on short time scales and are lost within the average structure that is dominated by the more static Coulombic lattice of alternating cations and anions.

Flipping of imidazole rings as the mechanism for $\mathrm{H}$-exchange and proton conductivity in crystalline imidazole was proposed by Kawada et al. ${ }^{37}$ in 1970. Li et al. ${ }^{38}$ modelled proton transfer in liquid imidazole, identifying [Im-imid-Im] + cation formation through solvation of protonated imidazolium cations (generated by reaction with injected protons) by imidazole. Within the simulations, proton transfer was considered as a local event with only very short spatial/temporal correlation whereas slower imidazole reorientation was identified as the rate limiting step. Simulating the properties of ionic liquids, Zhang and Maginn ${ }^{39}$ show that there was a linear inverse relationship between calculated ideal ionic conductivity and ion-pair and ion-cage lifetimes suggesting that relative conductivity is dominated by the dynamics of the formation and breaking of ion pairs or cages structures. Notably short ion-pair and ion-cage life time constants ( $\tau_{I P}=365 \mathrm{ps}$ and $\tau_{I C}=39.3 \mathrm{ps}$ at $380 \mathrm{~K}$ ) were calculated for [imidazolium] $\left[\mathrm{NTf}_{2}\right.$ ] indicating that local ionic structure reorganisation is an extremely dynamic process.

\section{Conclusion}

We set out with the objective of identifying whether complex imidazole-imidazolium cations were formed by hydrogen bonding within the basic part of the imidazole + bis $\{$ (trifluoromethyl)sulfonyl $\}$ imidic acid PIL phase diagram. We did not directly observe the existence of discrete complex cations, for example of the form shown in Fig. 3. The results obtained lead to a slightly different, more dynamic interpretation of the liquid structure, even though the analysis is for a static system which averages total liquid structure. ${ }^{\text {DOI: 10.1039/C7FD00143F }}$

Both 1:1 and 2:1 compositions reveal the presence of the characteristic ionic liquid cation-anion shell structure motifs, with imidazolium cations surrounded by anions with peak maximum at ca. $4 \AA$ in their first coordination shell, extending to $c a .7 .5 \AA$. The imidazolium cations are then surrounded, in a second ionic shell by cations arrayed at $6 \AA$ from the imidazolium COM. The 2:1 imidazole:acid system (containing imidazolium cations, $\left[\mathrm{NTf}_{2}\right]^{-}$anions, and neutral imidazoles) also shows additional imidazoliumimidazole and imidazole-imidazole correlations, both centred at a $5 \AA$ A separation between the rings.

The presence of $\mathrm{N}-\mathrm{H} \cdots$ anion oxygen hydrogen-bonding is consistent with Watanabe et al. ${ }^{34}$ and both the reduction in the magnitude of the cation...anion correlations and the significant change to the $\left[\mathrm{NTf}_{2}\right]^{-}$anion cis/trans conformer populations on changing from the $1: 1$ to $2: 1$ compositions reflect reductions in the strength of cation-anion hydrogen-bonding 23 as additional imidazole is added to the $1: 1$ [imidazolium] $\left[\mathrm{NTf}_{2}\right]^{-}$PIL. Adding imidazole (2:1 case) leads to the generation of imidazoleimidazolium and imidazole-imidazole correlations in the liquid. These demonstrate the formation of cation-base interactions at the expense of existing cation-anion hydrogen-bonding interactions, and are compensated for by the additional imidazolecation interactions. Imidazole-imidazole correlations were not anticipated, but appear consistent with recent work by Yaghini et al. ${ }^{32}$ where similar results were observed from vibrational spectroscopy and MD simulation.

The absence of specific $\mathrm{N}-\mathrm{H} \cdots \mathrm{N}$ correlations indicates that putative hydrogen-bonds between rings are temporal features within the overall structure of the liquid. However, heterocycleheterocycle association (imidazole/imidazolium) in the liquid occurs with COM correlations at $5 \AA$. The rings are positioned ideally relative to each other to interact via hydrogen-bonds enabling proton transfer through heterocycle reorientation without the need for any diffusional motion. Consequently, we can propose that, in the basic regime of this PIL, heterocycles are positioned relative to each other at distances ideally organised to allow transient hydrogen bonding without any diffusional motion. This allows a pathway for hydrogen transfer. The clearly prevalent random distribution of rings within the rotational gyroid strongly supports hydrogen mobility through flip-flop motion (Grotthuss mechanism), at least within the local environment, without requiring any diffusion (vehicle mechanisms).

\section{Acknowledgements}

We thank the Department of Education and Learning in Northern Ireland (DEL) for PhD studentships (AHT) and the Science and Technology Facilities Research Council (STFC) for beam-time on SANDALS (ISIS experiment RB1510225).

\section{References}

1 (a) T. L. Greaves and C. J. Drummond, Chem. Rev., 2015, 115, 11379-11448; (b) T. L. Greaves and C. J. Drummond, Chem. Rev., 2008, 108, 206-237.

2 J. Estager, J. D. Holbrey and M. Swadźba-Kwaśny, Chem. Soc. Rev., 2014, 43, 847-886. 
3 M. A. B. H. Susan, A. Noda, S. Mitsushima and M. Watanabe, Chem. Commun., 2003, 938-939.

4 M. Yoshizawa, W. Xu and C. Angell, J. Amer. Chem. Soc., 2003, 125, 15411-15419.

5 A. Noda, M. A. B. H. Susan, K. Kudo, S. Mitsushima, K. Hayamizu and M. Watanabe, J. Phys. Chem. B, 2003, 107, 4024-4033.

6 M. Watanabe, Materials Integration, 2003, 16, 33-39.

7 M. A. B. H. Susan, A. Noda and M. Watanabe, Proc. - Electrochem. Soc., 2006, 2004-24, 53-63.

8 H. Nakamoto, A. Noda, K. Hayamizu, S. Hayashi, H.-o. Hamaguchi and M. Watanabe, J. Phys. Chem. C, 2007, 111, 15411548.

9 H. Nakamoto and M. Watanabe, Chem. Commun., 2007, 2539-2541.

10 S.-Y. Lee, A. Ogawa, M. Kanno, H. Nakamoto, T. Yasuda and M. Watanabe, J. Amer. Chem. Soc., 2010, 132, 9764-9773.

11 M. S. Miran, T. Yasuda, M. A. B. H. Susan, K. Dokko and M. Watanabe, J. Phys. Chem. C, 2014, 118, 27631-27639.

12 M. L. Hoarfrost, M. Tyagi, R. A. Segalman and J. A. Reimer, J. Phys. Chem. B, 2012, 116, 8201-8209.

13 A. L. Chong, M. Forsyth and D. R. MacFarlane, Electrochimica Acta, 2015, 159, $219-226$.

14 S. P. Kelley, A. Narita, J. D. Holbrey, K. D. Green, W. M. Reichert and R. D. Rogers, Crystal Growth \& Design, 2013, 13, 965-975.

15 S. Kong, A. O. Borissova, S. B. Lesnichin, M. Hartl, L. L. Daemen, J. Eckert, M. Y. Antipin and I. G. Shenderovich, J. Phys. Chem. A, 2011, 115, 8041-8048.

16 T. G. A. Youngs, J. D. Holbrey, C. L. Mullan, S. E. Norman, M. C. Lagunas, C. D’Agostino, M. D. Mantle, L. F. Gladden, D. T. Bowron and C. Hardacre, Chem. Sci., 2011, 2, 15941605.

17 C. Hardacre, J. D. Holbrey, C. L. Mullan, M. Nieuwenhuyzen, T. G. A. Youngs, D. T. Bowron and S. J. Teat, Phys. Chem. Chem. Phys., 2010, 12, 1842-1853.

18 C. Hardacre, J. D. Holbrey, M. Nieuwenhuyzen and T. G. A. Youngs, Acc. Chem. Res., 2007, 40, 1146-1155.

19 S. Coffie, J. M. Hogg, L. Cailler, A. Ferrer-Ugalde, R. W. Murphy, J. D. Holbrey, F. Coleman and M. Swadzba-Kwasny, Angew. Chemie Int. Ed., 2015, 54, 14970-14973.

20 J. A. McCune, P. He, M. Petkovic, F. Coleman, J. Estager, J. D. Holbrey, K. R. Seddon and M. Swadźba-Kwaśny, Phys. Chem. Chem. Phys., 2014, 16, 23233-23243.

21 J. A. McCune, A. H. Turner, F. Coleman, C. M. White, S. K. Cal-
View Article Online

lear, T. G. A. Youngs, M. Swadźba-Kivasiny and J. D. Holbrey, Phys. Chem. Chem. Phys., 2015, 17, 6767-77.

22 J. Foropoulos Jr and D. D. DesMarteau, Inorg. Chem., 1984, 23, 3720-3723.

23 A. M. Moschovi, V. Dracopoulos and V. Nikolakis, J. Phys. Chem. B, 2014, 118, 8673-8683.

24 A. K. Soper, GudrunN and GudrunX: Programs for correcting raw neutron and $X$-ray diffraction data to differential scattering cross section, RAL-TR-2011-013, Rutherford Appleton Laboratory technical report, 2011.

25 A. K. Soper, Chem. Phys., 1996, 202, 295-306.

26 A. K. Soper, Mol. Phys., 2001, 99, 1503-1516.

27 Y. M. Delavoux, M. Gilmore, M. P. Atkins, M. SwadzbaKwasny and J. D. Holbrey, Phs. Chem. Chem. Phys., 2017, 19, 2867-2876.

28 A. H. Turner and J. D. Holbrey, J. Solution Chem., 2015, 44, 621-633.

29 Y. Zhang and E. J. Maginn, J. Phys. Chem. B, 2012, 116, 10036-48.

30 D. T. Bowron, C. D’Agostino, L. F. Gladden, C. Hardacre, J. D. Holbrey, M. C. Lagunas, J. McGregor, M. D. Mantle, C. L. Mullan and T. G. A. Youngs, J. Phys. Chem. B, 2010, 114, 77607768.

31 C. Hardacre, J. D. Holbrey, C. L. Mullan, M. Nieuwenhuyzen, T. G. A. Youngs and D. T. Bowron, J. Phys. Chem. B, 2008, 112, 8049-8056.

32 N. Yaghini, V. Gomez-Gonzalez, L. M. Varela and A. Martinelli, Phys. Chem. Chem. Phys., 2016, 18, 23195-23206.

33 C. Mao, Z. Wang, P. Ji and J.-P. Cheng, J. Org. Chem., 2015, 80, 8384-8389.

34 H. Watanabe, H. Doi, S. Saito, M. Matsugami, K. Fujii, R. Kanzaki, Y. Kameda and Y. Umebayashi, J. Mol. Liq., 2016, 217, 35-42.

35 M. Deetlefs, C. Hardacre, M. Nieuwenhuyzen, O. Sheppard and A. K. Soper, J. Phys. Chem. B, 2005, 109, 1593-1598.

36 T. F. Headen, C. A. Howard, N. T. Skipper, M. A. Wilkinson, D. T. Bowron and A. K. Soper, J. Am. Chem. Soc., 2010, 132, 5735-5742.

37 A. Kawada, A. R. McGhie and M. M. Labes, J. Chem. Phys., 1970, 52, 3121-3125.

38 A. Li, Z. Cao, Y. Li, T. Yan and P. Shen, J. Phys. Chem. B, 2012, 116, 12793-12800.

39 Y. Zhang and E. J. Maginn, J. Phys. Chem. Letts., 2015, 6, 700-705. 